\title{
A 35-year-old man with a positive Lyme test result from a private laboratory
}

\author{
Nisha Andany MD, Savannah Cardew MD, Paul E. Bunce MD
}

See also page 1193 and www.cmaj.ca/lookup/doi/10.1503/cmaj.150874

Competing interests: None declared.

This article has been peer reviewed.

The clinical scenario is fictional.

Correspondence to:

Paul Bunce,

paul.bunce@uhn.ca

CMAJ 2015. DOI:10.1503 /cmaj.141413
A 35-year-old man with a 12-month history of fatigue is concerned about Lyme disease. He has not lived in or travelled to a Lyme endemic area. His physical examination and blood work, including complete blood count, electrolytes, creatinine, liver enzymes and thyroid function tests, are normal. Lyme serology conducted by a provincial public health laboratory has a negative result. The patient undertakes Lyme testing through a commercial laboratory in the United States, which shows a positive result. $\mathrm{He}$ asks his physician if he should be given antibiotics for Lyme disease.

\section{Are the patient's symptoms consistent with Lyme disease?}

Lyme disease is the most common vector-borne infection in North America ${ }^{1,2}$ and incidence in Canada is increasing, with more than 500 cases reported in 2013. ${ }^{3}$ However, this patient is very unlikely to have Lyme disease because he lacks both a compatible epidemiologic exposure and clinical findings of Lyme infection.

The cause of Lyme disease, Borrelia burgdorferi, is transmitted to humans through the bite of infected blacklegged ticks (Ixodes scapularis or Ixodes pacificus). ${ }^{1}$ Most infections occur during spring and summer, and transmission is uncommon if tick attachment is less than 36 hours. ${ }^{1}$ Infected ticks have now established endemic populations in several Canadian provinces, including British Columbia, Manitoba, Ontario, Quebec and Maritime provinces. ${ }^{3}$

The signs and symptoms of Lyme disease are categorized into three stages (Box 1). ${ }^{1}$ Untreated Lyme disease may progress to later stages of infection. ${ }^{1}$ The term "chronic Lyme disease" is sometimes used to describe a number of later stage syndromes, but lacks a consistent definition. It is occasionally applied to cases in which patients have late neurologic Lyme disease - neuroborrelosis - but such patients have active infection and fall within stage 3. Similarly, some patients with untreated Lyme arthritis will have symptoms for months or years, but are also classified in stage $3 .{ }^{4} \mathrm{~A}$ subset of patients with confirmed and appropriately treated Lyme disease will have persistent symptoms beyond six months in the absence of objective clinical findings, which is termed post-Lyme disease syndrome. ${ }^{1,4}$

\section{Why does this patient have discrepant test results for Lyme disease?}

Lyme disease can be diagnosed either clinically or by appropriate serologic testing. A clinical diagnosis can be made in patients with erythema migrans and plausible exposure. ${ }^{1,5}$ Because this patient does not report a rash at the onset of his illness, he would require a positive serologic test result for diagnosis. However, only patients with compatible objective findings and a reasonable epidemiologic exposure should undergo testing. Testing is discouraged for patients with nonspecific symptoms owing to the poor predictive value and possibility of false-positives. ${ }^{1,5}$

The standard test for Lyme disease consists of a two-tier strategy performed in accredited laboratories ${ }^{1}$ in accordance with recommendations from the Infectious Diseases Society of America (IDSA) and the Centers for Disease Control and Prevention (CDC),,${ }^{1,2}$ and is the approach employed by Canadian public health laboratories. ${ }^{5}$ Enzyme immunoassay is used for the initial screening. If the result is negative, no further testing is done. If the result is positive or equivocal, a Western blot is used for confirmation of the results. ${ }^{1,2}$ The results are interpreted in accordance with CDC guidelines. Antibodies typically develop within four to six weeks, at which point sensitivity of the twostep protocol is about $87 \%$ and specificity is about $99 \% .{ }^{6}$ False-negative results may occur 


\begin{tabular}{|c|c|c|}
\hline $\begin{array}{l}\text { Stage of } \\
\text { disease }\end{array}$ & Syndrome & Description \\
\hline 1 & Erythema migrans & $\begin{array}{l}\text { - Large, red lesion with central clearing ("target lesion") at } \\
\text { the site of the initial tick bite } \\
\text { - May be accompanied by fever, headache and joint pain }\end{array}$ \\
\hline \multirow[t]{2}{*}{2} & $\begin{array}{l}\text { Neurologic Lyme disease } \\
\text { (neuroborrelosis) }\end{array}$ & $\begin{array}{l}\text { - Cranial nerve palsy, with or without meningitis } \\
\text { - Lyme meningitis } \\
\text { - Lyme radiculopathy }\end{array}$ \\
\hline & $\begin{array}{l}\text { Cardiovascular Lyme } \\
\text { disease }\end{array}$ & $\begin{array}{l}\text { - Heart block } \\
\text { - Myocarditis } \\
\text { - Pericarditis }\end{array}$ \\
\hline \multirow[t]{4}{*}{3} & Arthritis & - One or multiple joints at a time \\
\hline & $\begin{array}{l}\text { Late neurological Lyme } \\
\text { disease }\end{array}$ & $\begin{array}{l}\text { - Encephalopathy } \\
\text { - Encephalitis } \\
\text { - Peripheral neuropathy }\end{array}$ \\
\hline & $\begin{array}{l}\text { Acrodermatitis chronica } \\
\text { atrophicans }\end{array}$ & $\begin{array}{l}\text { - Skin discolouration and swelling that can occur up to } 8 \text { years } \\
\text { after initial infection }\end{array}$ \\
\hline & $\begin{array}{l}\text { Post-Lyme disease } \\
\text { syndrome }\end{array}$ & $\begin{array}{l}\text { - Subjective symptoms after treatment without objective } \\
\text { clinical findings }\end{array}$ \\
\hline
\end{tabular}

in early stage disease, when the sensitivity of the two-step protocol is about $40 \% .^{6}$

Clinicians should be aware that several commercial laboratories offer Lyme testing, but that the diagnostic techniques used are unvalidated and have poor test characteristics (e.g., urine antigen tests, CD57 antigen testing, polymerase chain reaction [PCR] testing, immunoblot with in-house interpretation not adherent to CDC standards). ${ }^{2}$ Molecular detection methods for Lyme disease, such as PCR testing, are problematic for several reasons, including the complexity of Borrelia burgdorferi's antigenic composition, the sparse bacterial loads in clinical samples, the differences in assays and genetic targets and their limited clinical validation. ${ }^{7}$ In addition, PCR techniques are subject to contamination, and false-positives have been reported. ${ }^{8}$ Thus, antibody detection has become the mainstay of diagnosing Lyme disease.

The utility of Western blot testing requires standardized methods and interpretation of the results. ${ }^{9}$ The current guidelines for interpreting Western blot results recommended by the CDC are based on the systematic evaluation of these diagnostic tools. During acute infection (within 4 weeks), both immunoglobulin $\mathrm{M}$ and $\mathrm{G}$ immunoblots are required; infection beyond four weeks should be evaluated with immunoglobulin G immunoblot only. ${ }^{9}$ These recommendations take into account the variability in interpretation and the reduction in specificity when immunoglobulin $\mathrm{M}$ immunoblots are done in cases where illness has lasted for more than 1 month. ${ }^{5}$ The performance of the Western blot when used and interpreted outside of these criteria is unclear. ${ }^{4}$

\section{Should antimicrobial therapy be offered to this patient?}

Treatment recommendations for Lyme disease are outlined in the IDSA guideline ${ }^{1}$ and vary with the stage of infection. This patient does not have objective clinical evidence of early Lyme infection (i.e., erythema migrans), which is the only stage of infection that should be treated empirically. In all other cases of suspected Lyme disease, infection should be documented with serology based on standardized testing protocols before any treatment is started. Antimicrobial therapy should not be offered to patients with chronic subjective symptoms but negative serology results from a public health laboratory, such as this patient. ${ }^{1}$ Symptoms may persist for months or years after appropriate treatment in patients with post-Lyme disease syndrome. However, evidence from randomized controlled trials has shown that prolonged antibiotic therapy is associated with no or minimal benefit and increased adverse events in these patients. ${ }^{1,4}$

\section{The case revisited}

This patient has not resided in a Lyme endemic area and lacks objective clinical or validated laboratory findings of Lyme infection. He should be counselled that the methods used by the private laboratory are nonstandardized and may lack the appropriate reliability and validity to establish a diagnosis, and that the testing method used in public health laboratories is the current accepted 
standard. Antimicrobial therapy is not recommended and could potentially lead to adverse events, including Clostridium difficile infection and vascular catheter-associated complications (were the patient to receive antimicrobial agents intravenously). If there had been a history of potential Lyme exposure in the last four to six weeks, testing at a public health laboratory could be repeated to look for convalescent serology; otherwise, the patient should undergo evaluation for alternative causes for his symptoms.

\section{References}

1. Wormser GP, Dattwyler RJ, Shapiro ED, et al. The clinical assessment, treatment, and prevention of Lyme disease, human granulocytic anaplasmosis, and babesiosis: Clinical Practice Guidelines by the Infectious Diseases Society of America. Clin Infect Dis 2006;43:1089-134.

2. Lyme disease. Atlanta (GA): Centers for Disease Control and Prevention; 2015 [modified]. Available: www.cdc.gov/lyme/ (accessed 2014 June 26).

3. Lyme disease. Ottawa: Public Health Agency of Canada; 2015 [modified]. Available: www.phac-aspc.gc.ca/id-mi/lyme-eng. php (accessed 2015 Aug. 13).

4. Feder HM, Johnson BJB, O'Connell S, et al. A critical appraisal of "chronic Lyme disease" [published erratum in N Engl J Med 2008;358:1084]. N Engl J Med 2007;357:1422-30.

5. The Canadian Public Health Laboratory Network. The laboratory diagnosis of Lyme borreliosis: guidelines from the Canadian Public Health Laboratory Network. Can J Infect Dis Med Microbiol 2007; 18:145-8.

6. Hinckley AF, Connally NP, Meek JI, et al. Lyme disease testing by large commercial laboratories in the United States. Clin Infect Dis 2014;59:676-81.
7. Dumler JS. Molecular diagnosis of Lyme disease: a review and meta-analysis. Mol Diagn 2001;6:1-11.

8. Molloy PJ, Persing DH, Berardi VP. False-positive results of PCR testing for Lyme disease. Clin Infect Dis 2001;33:412-3.

9. Engstrom SM, Shoop E, Johnson RC. Immunoblot interpretation criteria for serodiagnosis of early Lyme disease. J Clin Microbiol 1995;33:419-27.

Affiliations: Department of Medicine (Andany, Cardew, Bunce), University of Toronto; Division of General Internal Medicine (Cardew), Women's College Hospital Toronto; Division of Infectious Diseases (Bunce), University Health Network, Toronto, Ont.

Contributors: All authors were involved in the conceptualization and design of the manuscript. Nisha Andany prepared the initial draft, which was subsequently revised by Paul Bunce and Savannah Cardew. All of the authors have approved the final version of the manuscript and agree to act as guarantors of the work.

Decisions is a series that focuses on practical evidence-based approaches to common presentations in primary care. The articles address key decisions that a clinician may encounter during initial assessment. The information presented can usually be covered in a typical primary care appointment. Articles should be no longer than 650 words, may include one box, figure or table and should begin with a very brief description (75 words or less) of the clinical situation. The decisions addressed should be presented in the form of questions. A box providing helpful resources for the patient or physician is encouraged. 